\title{
En las bases de la ontología*
}

\author{
Miguel García-Baró**
}

Pontificia Universidad de Comillas

Recibido: 26 de noviembre de 2009 • Aprobado: 6 de diciembre de 2009

Este artículo retoma la tradición del discurso ontológico en sus dimensiones epistemológicas y lógico-argumentativas, para sostener la apertura del sentido de la interpretación como campo de exploración de la autoconciencia, puesto que toda interpretación es al mismo tiempo un ejercicio de'autointerpretación'. En este sentido, las categorías de verdad, absoluto, ser y conocimiento, entre otras, son revisadas desde el horizonte del lenguaje, específicamente en las manifestaciones lingüístico-semióticas del sujeto en su proceso de relación con las cosas y con el mundo, generando en dicho proceso formas de auto-reconocimiento y auto-interpretación.

Palabras clave: ontología, conocimiento, interpretación, significado.

* Este texto es un producto de los talleres de investigación en torno a los presupuestos ontológicos de la filosofía, los cuales se imparten en la Universidad de Comillas (Madrid).

** Doctor en Filosofía y profesor de la Universidad de Comillas (Madrid, España). Entre su amplia trayectoria como escritor de filosofía e investigador, cabe destacar las obras La verdad y el tiempo (1993), Categorías, intencionalidades y números (1993), Ensayos sobre lo absoluto (1993), Edmund Husserl (1997), Vida y mundo. La práctica de la fenomenología (1999), Introducción a la teoría de la verdad (1999), De Homero a Sócrates. Invitación a la filosofía (2004). Es miembro asociado del Círculo Latinoaméricano de Fenomenología (CLAFEN). Correo electrónico: mgbaro@chs.upcomillas.es 


\section{On the foundations of ontology}

\section{A bstract}

This article retakes the tradition of the ontological discourse on its epistemologic and logic-argumentative dimensions, to support the opening of the sense of the interpretation as a field of exploration of the self-conscious, therefore, the interpretation is at the same time an exercise of self-interpretation. On this sense, the categories of truth, absolute, being and knowledge, among others, are checked from the language horizon, specifically on the linguistic-semiotic manifestation of the subject on their relation process between things and the world, generating as a consequence on that process ways of self-recognition and self-interpretation.

Key Words: Ontology, knowledge, interpretation, meaning. 


\section{Dans les bases de I 'ontologie}

\section{Résumé}

Cet article reprend la tradition du discours ontologique dans ses dimensions épistemologiques et logico- argumentatives pour soutenir l'ouverture du sens de l' 'interprétation comme champs d'exploration.de l'auto-conscience puisque toute l'interprétation resulte en même temps un exercice d'autointerprétation comme champú d'activité. Dans ce sens les catégories sur la vérité l'absolu, l'être et le la connaissance ont subi une révison de I'horizon du langage, spécifiquement dans les manifestations lingüístique-sémiotiques du sujet dans son processus de relation avec les choses, les formes d'autoreconnaissance et d'auto interprétation.

Mots clés: Ontologie, connaissance, interprétation, signification. 


\section{I}

Ahora que la filosofía se desconoce y se denigra, importa muchísimo derribar fronteras estúpidas tras las que parece que se parapeta un gremio de especialistas. Las cuestiones de la filosofía son universales, decisivas y apasionantes. Quien lo ve tiene el deber de presentarlas con toda la sencillez que sea compatible con no hacerles perder nada de su alcance, su sabor y su hondura.

Pues bien, la teoría acerca de la intencionalidad de la conciencia es el nudo central de todos los problemas de la filosofía. Pero este término -"intencionalidad de la conciencia"- es hoy, sin duda, una palabra técnica, propia de la jerga profesional. ¿De qué hablamos? Hablamos del modo, extraordinariamente admirable, inagotablemente admirable, como nuestra conciencia, nuestra vida, revela el valor, la existencia y el contenido de todo cuanto es, a la vez que quizá también encubre y desfigura muchas cosas. Cuanto existe y es importante, cuanto no existe y no es importante, se nos presenta, se nos manifiesta de alguna manera. Lo que se nos presenta podemos Ilamarlo también, con un término clásico, la totalidad de los fenómenos. Cuando hablo de "conciencia" me refiero, justamente, a la presencia, a la revelación o manifestación de esta totalidad de los fenómenos; una manifestación que a su vez es patente. La conciencia de las cosas es al mismo tiempo conciencia de sí misma, autoconciencia.

No creo que quepa dividir el infinito campo de las investigaciones y la meditación humanas de manera más abarcadora y satisfactoria que en los dominios. Ante todo, el de aquello que existe, sea como quiera, que posee alguna clase de entidad, todo lo que cabe colocar en la posición de sujeto gramatical de una afirmación verdadera que siga alguno de estos modelos: "esto existe", "esto es tal y tal", "esto está en tales y tales relaciones con esto otro o estos otros" $y$ "esto posee tales y tales partes".

En segundo lugar, un dominio mucho más restringido: ¿qué significan ser, existiry estar en estas frases que acabo de entrecomillar? El primer campo es, en la terminología clásica, el de los entes; el segundo, en esta misma termino- 
logía, el del ser de los entes. La filosofía llama ontología a la investigación en ambos terrenos. Si se los quiere diferenciar, habrá que decir que el primero es el propio de las ontologías regionales o materiales (puesto que hay regiones de entes muy distintas) y el segundo, el de la ontología fundamental (puesto que sin tener alguna concepción de lo que significa "ser" no se tiene ninguna de lo que significa"ente").

De los problemas ontológicos se diferencian los que se refieren al deber ser, al valer; no a los "valores" como tipos peculiares de entes, sino a aquello que debe ser y vale, precisamente en su diferencia respecto de cualquier clase de mero ser. Lo habitual ha sido hablar, a propósito de este nuevo género de investigaciones, de ética. Pero la palabra se queda corta cuando consideramos que lo esencial aquí es comprender que la aventura moral y, en general, nuestra existencia, en el sentido de nuestro jugarnos la vida en la responsabilidad, en la alternativa de salvarse o perderse uno mismo y a otros, por más relaciones que pueda tener entabladas con el puro ser, de ninguna manera se confunde con una especie estática de entidad que precisamente se vea privada de la dimensión de la libertad, el futuro, el bien y el mal, el amor y el odio, la victoria y la liberación, el fracaso y la aniquilación. Como correlato de "ontología", habría aquí que introducir una palabra prácticamente nueva: "agatología", es decir, la investigación no del ser sino del bien (y su contrario).

La cuarta esfera de los posibles temas de nuestra preocupación y nuestra teoría es la del pensamiento, la del conocimiento y el discurso y la investigación. Un terreno esencialmente reflexivo y no directo hacia las cosas, una vuelta desde la totalidad de los fenómenos (los entes y su ser, los bienes y su bondad) hacia la conciencia de esa totalidad. Aquí, en la lógica amplia y clásicamente entendida, el problema es cómo son para nosotros problemas y temas todos los problemas y todos los temas. Además del ser y el valer, tenemos, efectivamente, que contar con el hecho de que ambos aparecen, son pensados, son objetos intelectuales; y es claro que la manifestación no se confunde con aquello que ella manifiesta.

No nos preguntemos ya ahora -por lo menos, no tan explícitamente como para quedar de entrada atrapados en la suprema dificultad de la cuestión-por la unidad del ámbito infinito dentro del cual hemos diferenciado estos tres 
miembros (lo ontológico, lo agatológico y lo lógico). Al menos de momento, no tenemos nombres ciertos para esta unidad última, que algunos Ilamarían seguramente la vida.

\section{II}

Fenómeno, manifestación, apariencia es cosa que requiere tres elementos constitutivos: lo que aparece (ya sea ente, valor y libertad o pensamiento), aquel ante quien aparece y el contenido exacto que se convierte en dato de la cosa para el sujeto. Si no nos ligamos a ninguna teoría pasada, podemos hablar, respectivamente, para simplificar, de la cosa, el sujeto y el objeto. Son palabras cargadísimas de historia, pero nosotros, como siempre que se inicia el movimiento de la filosofía en alguien y desde alguien, tenemos la estricta necesidad de desprendernos de las tradiciones que tienden a indicarnos el camino por donde habremos de ir, antes de que sean las cosas mismas quienes lo hagan.

La "cosa", podemos también decir, es sólo el polo que atrae nuestro interés teórico. El "sujeto" somos nosotros mismos, los que vivimos este interés y quizá lo vamos pudiendo satisfacer poco a poco. El "objeto" es aquí simplemente lo conocido en cuanto tal, lo que en nuestra teoría ya hemos conquistado de aquello que nos interesa. Pero con una reserva importantísima: al ser el conocimiento manifestación de la cosa en el sujeto, queda por principio abierta la vía a la posibilidad de que la manifestación sea inadecuada. La inevitable interpretación que el sujeto ha de hacer de todo fenómeno puede errar, en cualquiera de los sentidos en que quepa errar.

Y es que en la primera aproximación a los datos no he contabilizado uno, a saber: que el conocimiento deberá suponer siempre cierta mediación. En él se echará estructuralmente de menos una imposible inmediatez: la de la presencia absoluta de la cosa "dentro" del sujeto. Una cosa que pasa a formar parte de otra es una cosa ingerida, tragada o incrustada en otra cosa; pero jamás es una cosa conocida por un sujeto. En tanto que tales, el sujeto y la cosa no existen del mismo, y es absurdo pensarlos en tal homogeneidad el uno con la otra que llegue a ser posible esa ingerencia o incrustación de la 
cosa en nosotros. Más bien sucede que la asimilación cognoscitiva de las cosas por el sujeto requiere, por decirlo de algún modo, la destilación de todas las cosas en el material subjetivo que es lo que he denominado el objeto o el fenómeno.

Llegados aquí, podemos atrevernos a decir que el objeto es, entonces, el signo subjetivo de las cosas. Un signo es un signo cuando -y en la medida en que- envía a un sujeto hacia cierto significado. Esta función de manifestar algo otro es evidente que no se puede realizar más que si el signo (la cosa-signo) es captado por el sujeto como remitiendo a algo otro de sí mismo. Captar como es, al pie de la letra, interpretar el sentido y, mediante la interpretación, referir el signo a lo que él significa. $E$ insisto en que queremos en todo esto mantenernos desligados de cualquier compromiso con cualquier teoría del pasado y con cualquier comprensión presuntamente de "sentido común" que ya aporte la lengua materna en que nos expresamos.

Si ahora recontamos los elementos constitutivos del conocimiento, el resultado es este:

1) Cosa no subjetiva, trascendente al sujeto, heterogénea ontológicamente respecto de éste y, a la vez, polo de su interés teórico, cognoscendum.

2) Sujeto teóricamente interesado y en progresiva satisfacción de su carencia de verdad.

3) Fenómeno subjetivo, es decir, asimilable ontológicamente de alguna manera por el sujeto y esencialmente inmanente a éste, aunque tampoco homogéneo respecto del sujeto: signo de la cosa, cognitum.

4) Interpretación por parte del sujeto del fenómeno como tal fenómeno; es decir, captación del sentido del fenómeno como signo que envía hacia la cosa.

Si reparamos cuidadosamente en lo que estamos diciendo $-\mathrm{y}$ hay que tomarse tiempo para hacerlo, sin que yo añada más palabras-, vemos con evidencia que estos mismos elementos todavía pueden describirse con otras expresiones. Nos interesa variarlas y multiplicarlas, para que nuestra comprensión vaya avanzando con seguridad. Diremos que el objeto o fenómeno 
es el significante; la cosa, el significado o, mejor, lo significado; la interpretación es la atribución de sentido al significante, exactamente para que remita a tal significado; el sujeto es, entonces, primordialmente el intérprete.

En esta perspectiva, el conocimiento se presenta como un suceso que no es sino el acontecimiento de la interpretación. Hablo aquí sin querer definir con exactitud las diferencias entre suceso y acontecimiento, que en otros contextos son decisivas. Pues bien, este acontecimiento está esencialmente hecho posible por dos estructuras que lo trascienden, o sea, que no son meras partes del suceso. Me refiero a la cosa y al sujeto. Debo contar con los dos, pero precisamente a título de entidades que necesariamente preexisten al suceso cognoscitivo y necesariamente sobreviven a él. La cosa le sobrevive incólume; el sujeto, en cambio, se trasforma a sí mismo en la serie ininterrumpida de las interpretaciones.

La cosa, aunque no es, desde luego, del todo opaca para la razón, resiste, con la consistencia de la piedra, al proceso de su elaboración racional. No se desgasta por el tacto inmaterial del conocimiento. No tiene, en este preciso sentido, historia ni tiempo. Su modo de ser es, por decirlo de alguna manera, la pura permanencia en sí misma. Incluso sus trasformaciones son ahistóricas, puesto que le sobrevienen como zarpazos o incrementos de los que ella carece de noticias.

El sujeto es, por su parte, la historia de las interpretaciones: puro tiempo que consiste en tendencia a lo otro de sí; en búsqueda, encuentro y búsqueda alimentada por el caudal constante de los sucesos y los acontecimientos, que son, respectivamente, renovados o imprevisibles encuentros. Mientras que para la cosa no hay propiamente acontecimiento ni suceso, el sujeto es el suceso de todos los sucesos, el acontecimiento de todos los acontecimientos; o, más bien, la tensión subyacente que los hace posibles a todos.

Sin embargo, el registro de los componentes básicos del conocimiento no está aún, ni mucho menos, concluido. Baste citar un quinto ingrediente imprescindible, que, sin duda, viene a perturbar radicalmente (es decir: a aclarar radicalmente) el relativo orden que hemos alcanzado a establecer entre los datos del problema. Este quinto factor es el hecho de que la interpretación es 
un suceso que acontece ante sí mismo, o, expresado con más exactitud: que la interpretación es transparente para sí misma; que se sabe a sí misma; que tiene conciencia de cuanto ella es $y$, fundamentalmente, del hecho mismo de que está ahora teniendo lugar ("ahora", o sea: en determinada altura de la historia de un intérprete).

Es realmente esto lo que se quiere dar a entender cuando se dice, con cierta despreocupación, que el conocimiento es una vivencia consciente, un suceso en la conciencia de un sujeto. Y como subjetividad, historia y autoconciencia son para nosotros, hasta aquí, términos esencialmente inseparables, reconoceremos que hablar de la conciencia como de una facultad de cierta cosa llamada yo es un modo muy poco justo de describir lo que efectivamente ocurre. Lo que hay, más bien, y permítaseme la frase difícil, que exige ser pensada un momento antes de seguir leyendo de prisa, es que toda interpretación es 'autointerpretación', y que sólo puede serlo surgiendo en la historia global de las interpretaciones sucesivas que constituyen al menos una sustancial porción del sujeto.

Sólo ahora nos encontramos ante lo paradójico de la razón. Una paradoja esencial, que se puede desglosar, meramente porque no se puede decir todo a la vez, aunque se deba, en dos preguntas: ¿cómo es, en general, posible el acontecimiento de la interpretación? ¿Cómo es, en general, posible que toda interpretación sea 'autointerpretación'? Intentemos señalar lo más directamente posible la paradoja que casi se oculta detrás de estos dos interrogantes.

Respecto del primero, el misterio estriba en el origen último del sentido. No puede descubrirse algo acerca de lo cual se ignore absolutamente todo. No cabe ni siquiera preguntarse por lo que es absolutamente desconocido. Nada conocible es primeramente un absoluto desconocido. No se puede, pues, empezar jamás a entender. E incluso es un enigma que alguna vez pueda entenderse más de lo que de antemano (a priori del acontecimiento concreto de la interpretación) se entendía ya, pues también para este relativo desconocido tiene que haber un sentido disponible que lo esté esperando para satisfacerse plenamente en él. El enigma del origen de la interpretación, que se extiende, según vemos, a la historia de toda interpretación, es, 
justamente, nada menos que el misterio de la condición que hace posibles la historia, el sujeto, el tiempo y la autoconciencia.

Por lo que hace al segundo interrogante -no cabe separarlo tajantemente del primero-, la paradoja es que el hecho de que toda interpretación sea 'autointerpretación', pone de relieve lo difícil -por decirlo suavemente-que es considerar siempre el conocimiento un proceso signitivo. La interpretación del objeto está inmediatamente presente a sí misma. Aunque utilicemos la dura palabra 'autointerpretación', porque tampoco estamos aquí ante un caso de inclusión o incrustación simple de algo en un todo, sino ante un conocimiento certísimo y clarísimo, no podemos creer que la interpretación del sentido del objeto se nos da en un nuevo objeto-significante, que precisaría también de una interpretación, la cual, naturalmente, sólo se conocería mediada por la interpretación de ese otro signo destinado a presentárnosla, el cual, in infinitum, exigirá otro signo de sí, que exigirá otro más.

En cualquier grado de esta serie (lo que quiere decir que no hay razón para que no nos quedemos ya con el primero), la interpretación cognoscitiva tiene que ser un suceso inmediatamente presente, e inmediatamente presente a sí mismo, autopresente. La interpretación que en cierto momento llevo a cabo es, en otros términos, inmanente a mi existencia de sujeto histórico de un modo mucho más íntimo que aquel en el que hablo también de"inmanencia" y "subjetividad" a propósito del fenómeno cuyo sentido capto.

Hay, pues, al menos dos modos esencialmente distintos del conocimiento: la interpretación de objetos, de un lado y, del otro, la 'autointerpretación', absolutamente inmanente, de toda interpretación de objetos. Y en cuanto al sujeto histórico, la doble paradoja que hemos empezado a analizar no da sin más por cancelada la posibilidad de la historia; pero, eso sí, imposibilita que adoptemos, respecto del sujeto, la óptica de su plena y total historicidad, sin resto de eternidad. 


\section{III}

Antes de ir persiguiendo cada uno de los hilos variadísimos que se han revelado ya en estas exploraciones preliminares, a fin de que la dificultad extrema de los problemas, en contraste con la sencillez absoluta de las primeras descripciones, no nos desconcierte, puede ser útil echar una ojeada panorámica a la historia de la filosofía.

La más simple posición filosófica, el empirismo, se caracteriza esencialmente por recusar el factor interpretación. En la labor de llevar a perfección este programa que define a la filosofía empirista, hay formas muy mediocremente consecuentes de hacerlo. Así sucede con el trabajo de John Locke, quien no se atrevió a identificar cosas y objetos, por más que, como es evidente, si se rechaza la interpretación lo que efectivamente se rechaza es el carácter sígnico del conocimiento de lo trascendente y, en consecuencia, se debe negar lo trascendente mismo: hay que identificarlo con el objeto inmanente y subjetivo.

Se llama fenomenismo justamente a esta identificación, a esta reducción de la complejidad del fenómeno del conocimiento. En su sentido más estricto, el fenomenismo convierte, pues, al sujeto en el conjunto de las cosas, las cuales coinciden, a su vez, con los fenómenos. En este sentido tan duro, el fenomenismo es la culminación consecuente del empirismo.

El empirismo fenomenista encontró seguramente su realización más perfecta en las obras de David Hume y John Stuart Mill. Posee antecedentes en las especulaciones del materialismo antiguo (Demócrito, que más bien es un predecesor de Locke y, sobre todo, el genio de Epicuro). Los comienzos del empirismo fenomenista clásico están en la extraordinaria obra de George Berkeley. Sin embargo, este pensador previó la posición que pocos años después adoptaría David Hume y la rechazó por razones muy profundas que, por cierto, Hume nunca quiso discutir directamente. Ello llevó a Berkeley a renunciar al fenomenismo absoluto como un absurdo. El motivo esencial fue que tenía, con toda razón, como empresa completamente irrealizable la destrucción del sujeto (que es lo que resulta de su identificación con la totalidad de los fenómenos). 
Por su parte, la tendencia profunda de la filosofía racionalista conduce asimismo a la destrucción del sujeto, pero por la vía opuesta a la recorrida por Hume. Lo que aquí atrajo deslumbradoramente a la inteligencia fue en definitiva la imposibilidad de la historia, la imposibilidad de la novedad, la paradoja que encierra la noción de un origen absoluto de la interpretación.

El precursor antiguo de la realización de este programa filosófico es Parménides, el defensor de la unidad y la eternidad absolutas del ente. Habría que preguntarse si las escuelas de Elea y Mégara, el neoplatonismo y los distintos gnosticismos que lo rodean no han sido los más logrados intentos de pensamiento "racionalista" consecuente hasta el extremo.

Por otra parte, en la modernidad es seguramente Espinosa quien ha pensado el monismo intelectualista con más hondura, aunque cabría opinar que el racionalismo absoluto ha sido el que, en vez de negar simplemente la historia, la ha asumido en la Totalidad perfectamente racional, al modo en que, después del arduo esfuerzo de Leibniz, lo procuró Hegel. Descartes y Malebranche, sobre todo el Descartes pensador de las dos primeras Meditaciones metafísicas, son, respecto de la tradición racionalista, cosa análoga a la representada por Berkeley en la tradición empirista. También ese Descartes que digo pensó la irreductibilidad del yo finito como imposible de subsumir en la Totalidad donde la individuación queda abolida (aunque el filósofo racionalista diga que queda sobreelevada).

La filosofía de Aristóteles contiene muchos más elementos racionalistas que empiristas. Aristóteles quizá pueda ser situado en el lugar que separa a Espinosa de Leibniz. Platón, en cambio, respecto del cual es impropia la expresión "la filosofía de Platón", dado que su obra es una inmensa discusión abierta, paradójica, irónica e indirecta de prácticamente todos los problemas esenciales, será siempre el lugar clásico en donde el investigador encuentre factores descriptivos y piezas especulativas de extraordinario valor, que a él se le ofrecen allí en toda la fuerza de su enigma, como para poner a la prueba más fuerte su capacidad filosófica.

Cabe luego, naturalmente, la renuncia al pensamiento, que si es atrevida y poco consecuente, se expresará como la recusación de la verdad y de todo 
conocimiento, y si es auténtico y profundo escepticismo se volcará en relatos y ejemplos, en literatura dramática, épica, lírica, sapiencial y novelística, como ya ocurrió paradigmáticamente en Eurípides y se repite constantemente en la actualidad (Roth, Auster, Kundera, Oz).

La filosofía crítica, el "idealismo trascendental" de Kant, se presentó, frente al escepticismo y los "dogmatismos" racionalista y empirista, como una nueva posibilidad, una cuarta vía nunca ensayada antes de 1800, aunque hubiera tenido precursores sutiles en escritores como Pascal u Ockham. La filosofía crítica se parece, por una parte, al empirismo: no cree que el conocimiento humano se extienda más que a los fenómenos u objetos. Pero más aún se parece al racionalismo en su defensa del sentido de los fenómenos, por más que piense que este sentido no designa las cosas trascendentes. Procede, pues, a construir una noción nueva del objeto, puesto que lo distingue rigurosamente de la "cosa en sí" $y$, al mismo tiempo, sostiene que esta "cosa en sí" es absolutamente incognoscible. En el dominio de los fenómenos u objetos, distingue todavía entre significantes subjetivos y significados transsubjetivos, que Kant pretende haber probado que no se pueden identificar con las cosas o, como él prefería decir, con la "cosa en sí".

Desde la perspectiva de la filosofía crítica, es dogmática la posición que, más que afirmar explícitamente que las cosas son conocibles, vive creyéndolo de manera incontrolada e impensada. La filosofía que de verdad es postkantiana-lo que no le sucede a toda aquella que ha sido escrita desde 1800 hasta hoy- se caracteriza fundamentalmente por la renuncia a la noción misma de "cosa en sí." En unos casos, estas filosofías, que, naturalmente, se inclinan todas hacia cierta metafísica del sujeto, han creído explorar lo Absoluto; en otros, han considerado que sólo exponían la finitud de la existencia histórica. Ha habido formas de existencialismo que no han supuesto que la finitud histórica sea la totalidad de cuanto hay y admiten, pues, en modos diversos, lo Absoluto no conocible en la pura teoría. Otras han concedido explícita o tácitamente que, por decirlo de alguna manera, la finitud es lo absoluto. Algunos de los pensamientos teístas más profundos que ofrece la historia se enmarcan en la primera de estas clases de filosofía existencial, cuyo iniciador moderno es Kierkegaard. La filosofía francesa, desde Blondel y Bergson hasta Levinas, 
Chrétien, Henry, Lacoste y otros contemporáneos, basada en los precedentes de San Agustín, Maine de Biran y los ya mencionados Descartes y Pascal, discurre también por estas vías. Y lo mismo se puede decir de la llamada Escuela de Madrid a grandes rasgos.

El pensamiento de la finitud y la historia como absolutos se realiza muy poderosamente en las obras de Heidegger y Merleau-Ponty, ambas decisivamente influidas por el intento de conciliación avant la lettre que representó la fenomenología trascendental de Husserl. Sus dos antecedentes en el siglo antepasado son la antropología de la izquierda hegeliana (ante todo, Feuerbach) y la ultraantropología nietzscheana. Por otra parte, el empirismo de Hume y Mill ha encontrado una prolongación postkantiana en la filosofía "lingüística" que ha pretendido sustituir la subjetividad por la estructura del lenguaje, como ha sucedido, sobre todo, en las obras de Wittgenstein y Austin. Ahora bien, regresemos a la reflexión sistemática.

\section{IV}

Entre tantas direcciones como podemos ahora emprender, quizá la primera deba ser la de intentar un catálogo de los elementos ontológicos primordiales, o sea, de esos que parece que habrían de configurar el fondo de todas las demás ideas, si es que no es trabajo perdido el de la búsqueda de una ontología absolutamente general, absolutamente formal, que abarcara incluso de alguna manera las "cosas" propias del dominio de la agatología.

Ensayemos, pues, con la noción que es aparentemente la más primitiva: la de unidad. Unidad no quiere decir simplicidad. Unidad se opone, ciertamente, a pluralidad; pero de ésta es necesario distinguir al menos dos significados. En uno, pluralidad se refiere a conjunto o colección de unidades; en el otro, pluralidad designa colectivamente las partes de una unidad, que en este caso se llama un todo.

La unidad auténtica de una cosa, de un todo, debe ser distinguida cuidadosamente de la unidad derivativa e inauténtica de un conjunto de cosas. De hecho, el término "parte" no se usa para designar las unidades que entran 
en un conjunto (y que pueden no ser cosas o todos, sino unidades simples o, por qué no, partes de ciertas cosas, como también pueden ser unidades ficticias, meros "entes de razón").

En cuanto tales, las partes de las cosas o todos no poseen más que una unidad impropia, análoga, pero no idéntica, a la unidad impropia característica de los meros conjuntos. Salta esto a la vista por el hecho de que los conjuntos reúnen unidades, aunque sea en la acepción más laxa de la palabra que quepa; mientras que una parte, tomada estrictamente como tal parte, o sea, no desgajada ni diferenciada del todo en el que se halla, colabora a la unidad auténtica del todo, de la cosa, justamente porque ella, la parte, de por sí no tiene unidad propiamente dicha.

Pero en seguida se nos complica la noción de parte, ya que es evidente que no todas las partes cooperan en la misma medida y de la misma manera a fundar la unidad real del todo. De no ser por esta complicación, sería fácil tomar la "unidad" de cada parte en cuanto parte como unidad en potencia, frente a la unidad en acto que tiene el todo y que adquiriría cualquier parte al desmembrarse de él y convertirse en una cosa real (simple o compleja, o sea, todo a su vez). Si la situación fuera tan aparentemente sencilla, la unidad en acto iría indisolublemente vinculada con aquello en la cosa que reúne propia y auténticamente las partes; pero, a su vez, este factor tendría por principio que equipararse con la unidad en acto propia ya de lo absolutamente simple -si existe algo absolutamente simple, y no se ve claro que no esté prohibido que exista; al revés, parece que la estructura de los todos, si es tan elemental como intentamos verla de momento, exige que, en definitiva, las partes úlimas desprendibles del todo sean siempre simples-.

Ahí se nos revela que la aparente sencillez era sólo aparente, ya que no es precisamente tarea fácil concebir cómo es posible que una parte simple sólo posea unidad potencial y adquiera repentinamente unidad en acto nada más por ser liberada de su vínculo con otras partes. ¿Mediante qué transformación? Y ¿cómo liberar de un vínculo a lo que, por ser simple, no puede desprenderse de nada sin aniquilarse? 
Reconoceremos, pues, que se necesitan mayores precauciones en el análisis de la naturaleza de las partes. Por un lado, parece concebible que haya partes que son, a su vez, cosas-todos en potencia, o sea, que vienen ya equipadas con todo lo que se precisa para adquirir, en el instante en que se rompa su vínculo con la cosa-todo actual, la unidad real y actual de una cosa al mismo tiempo que la independencia de la antigua cosa-todo en que se encontraban provisionalmente.

Pero, por otro lado, se hace necesario pensar también en partes que carecen absolutamente de la capacidad de convertirse en cosas. Partes, pues, que de suyo, a priori, no pueden volverse independientes $y$, en consecuencia, cuya "unidad" no es unidad real o propia ni en acto ni en potencia. Parece que sería útil decir que tales partes, dado que no son separables en la realidad sino sólo en el análisis intelectual, no tienen más unidad que la meramente intelectual o pensada. El análisis que las distingue no puede denominarse real en el sentido pleno y fuerte de este término, sino que es análisis mental, distinción de razón. Lo que no quiere decir que tal análisis no diferencie contenidos que verdaderamente forman parte de la cosa, del todo. Las partes que no tienen unidad más que en el análisis intelectual de la cosa no son por ello menos partes auténticas de la cosa.

Cuando usamos en este contexto el término clásico "distinción de razón" no queremos, pues, decir, de ninguna manera, que lo que distingue esta distinción no exista de algún modo y sea, en cambio, el entendimiento quien lo insufla en las cosas. La idea que comporta la "distinción de razón" es, más bien, la de que la"unidad" de ciertas "partes" presentes verdaderamente en la cosa está abierta por esencia a la reunión con otras partes de la misma cosa. Pensar esta "unidad" es ya pensar la relación extremadamente íntima en que la parte que sólo posee "unidad intelectual" está con alguna otra parte en el todo real. En definitiva, la unidad meramente intelectual es uno de los lados de lo que, visto por su otro aspecto, resulta ser relación necesaria o, más exactamente, fundamento de una relación auténticamente necesaria o intrínseca, o sea, exigida por la naturaleza misma de al menos uno de sus fundamentos. 
He aquí, entonces, la última diferenciación que se impone a priori en el poblado terreno ontológico de las partes. Y es que una parte que sólo posee unidad de razón cabe que sea fundamento de una relación necesaria e intrínseca bien con otra parte (o con otras partes) de su mismo estatus ontológico, o bien con una parte dotada de unidad real en potencia. En este segundo caso, es evidente que no podemos hablar con la misma plenitud que en el primero de la necesidad e inteligibilidad de la relación, puesto que sólo por el lado de uno de sus fundamentos hay la necesidad absoluta de entrar en esa determinada relación.

En resumen, junto a las cosas reales -que apenas cabrá confundir con el sentido que dimos a la palabra "cosa" en la primera discusión del fenómeno del conocimiento-, junto a los todos reales, hemos encontrado, en los pasos iniciales de nuestro ensayo de ontología general, los conjuntos y las partes de las cosas reales. Las partes de las cosas han quedado divididas, a su vez, en cosas en potencia y partes dotadas sólo de unidad intelectual o de razón.

Este último tipo de unidad debe ser cuidadosamente distinguido de la pseudounidad del conjunto. Si decimos que la unidad del conjunto no es real sino meramente pensada, no debemos en ningún caso confundir esta unidad irreal y puramente arbitraria con la unidad que poseen las partes que, siendo ingredientes auténticos de la cosa, no son, sin embargo, unidades reales en potencia. La pseudounidad del conjunto no es fundamento de ninguna relación necesaria, intrínseca e inteligible con otra parte de cierto todo; aunque para los conjuntos en general, en virtud de su forma arbitraria, valgan las leyes de la aritmética, por ejemplo.

Quizá sea útil, recapitulando todas las ideas expresadas hasta aquí, hablar, a propósito de los elementos de la ontología, de conjuntos, cosas, partes y aspectos. Hay que subrayar que la distinción de estas cuatro primeras piezas de la teoría ontológica procede a priori. En especial, no ocurre que las partes y los aspectos se deslinden recíprocamente a posteriori de que atendamos a ciertas esferas de ejemplos (como puedan ser las cosas que se ofrecen a la vista y al tacto). En el mismo momento en que se concibe la idea de parte se piensa también la idea de la reunión de las partes; pero la reunión como tal no puede a su vez ser una parte propiamente dicha de la cosa, por más 
que sea un componente o ingrediente auténtico de ella.Y sin duda que lo es, puesto que, como ya señalé, está en relación esencial con la unidad actual y real de la cosa-todo. La reunión, el vínculo de las partes, no es parte sino aspecto de la cosa. Quien concibe el pensamiento de las partes, concibe ya por ello mismo el pensamiento de los aspectos verdaderamente constituyentes de las unidades reales.

Si reparamos bien en lo que llevamos hecho, notaremos que aquí la idea originaria, la idea-límite, es la de la cosa en acto, la cual, eso sí, sólo adquiere su pleno desarrollo cuando se conciben el conjunto y la parte y, por ello mismo, el aspecto. Pero detengámonos también a considerar que, paralelamente a las nociones de cosa, conjunto, parte y aspecto, hemos pensado, sin duda e imprescindiblemente, o sea, a priori, algunos elementos ontológicos más; por ejemplo: relación de vinculación arbitraria e irreal de las cosas en el conjunto, relación necesaria (recíproca o unidireccional) de los aspectos entre sí y con las partes, vinculación real de las partes en la cosa, etc.

Cosa, conjunto, parte y aspecto son los elementos ontológicos desde el punto de vista de la unidad en general. Pero es que la unidad no es pensable con independencia del puro pensamiento de la relación. Por ello, a los cuatro tipos de unidad les corresponden en la teoría ontológica las cuatro clases de la relación que, ordenadas de mayor a menor grado de inteligibilidad, son: 1) la relación entre dos o más aspectos; 2 ) la relación entre un aspecto y al menos una parte; 3 ) la relación entre dos o más partes; 4) la relación entre cosas. Pero hay más. Pensemos sólo en que, igual que concebimos conjuntos de conjuntos, concebimos también relaciones entre conjuntos.

Un problema básico de la teoría ontológica es si las relaciones pueden asimilarse a las unidades y estudiarse, en general, como constituyentes de unidades, como aspectos de unidades (salvo las relaciones arbitrarias características de los conjuntos); o si, a la inversa, cabe subsumir el punto de vista de la unidad en el panorama de una ontología puramente relacional. O si más bien sucede, como he postulado yo tácitamente, que la reducción no es posible en ninguno de los dos sentidos (lo que implica ya de suyo una cierta primacía de la idea de cosa, o sea, de unidad, ya sea un todo, ya sea una unidad simple). 
La laguna más sensible de estos análisis provisionales concierne, sin duda, a las unidades de orden superior al de la unidad fundamental, o de orden ínfimo o cero, de la cosa. Y es que las unidades que suponen cosas, que se fundan en cosas, no siempre, ni mucho menos, son irreales y arbitrarias, como en el caso de los conjuntos (a los que sólo impropiamente cabe denominar unidades "de orden superior"). Dentro de estas estructuras, la unidad actual de la cosa no tiene que pasar a la mera potencia, como si en ellas se tratara de cosas hechas de cosas. Así ocurre con las situaciones, que otros llaman estados de cosas y que también es frecuente denominar hechos; así ocurre también con los procesos y los sucesos o eventos y con las llamadas escenas. Por el momento, no importa clasificar y definir exhaustivamente todas estas unidades complejas. Esto sí: un hecho es una situación pasajera, contingente; otras situaciones son, en cambio, necesarias, y no les conviene en absoluto la denominación de hechos.

Las situaciones, en efecto, son seguramente las estructuras fundamentales en este ámbito de los objetos superiores dotados de unidad no irreal y arbitraria. La razón que obliga a admitirlas y a concederles esta primacía es la presencia indudable de las verdades, que va ya implicada en el mero hecho de que se hable acerca de los elementos de la ontología. El correlato objetivo de un enunciado (un enunciado es un sentido, no una cosa) sobre los elementos ontológicos no es, por ejemplo, simplemente uno de éstos sino, más bien, un "comportamiento" o "estado" en que se ve envuelto.

Que haya hechos o situaciones renueva vigorosamente el problema de la unidad y la relación. Y la presencia de la verdad inaugura esferas nuevas de problemas esenciales de la filosofía primera.

\section{V}

¿A qué llamamos una verdad?

Empleando la misma terminología que al comienzo, parece que debe contestarse: llamamos una verdad a una cosa realmente existente, conocida tal y como es, o sea, manifestada en un objeto inmanente que presenta la 
cosa al sujeto como un medio perfectamente trasparente. Es verdadero el conocimiento que, mediata o inmediatamente, alcanza las cosas tal y como son en sí mismas.

Se ve, pues, que la palabra "verdad", aun no siendo equívoca, posee una naturaleza tal que permite predicarla tanto de la cosa como del objeto y de la interpretación (y del sentido en que ésta capta el objeto). Acerquémonos a esta pluralidad de usos.

Si hablo de "conocer una verdad", entonces, desde los puntos de vista del objeto y de la cosa, caigo en la cuenta de que lo conocido (lo estrictamente sabido, aquello de lo que me estoy enterando en cierto momento) tiene una estructura particular: la propia de una situación, que se llama desde antiguo una categoría o predicación. La cosa conocida (y el objeto correspondiente) no es exactamente una mera cosa sino el estado de una cosa, la situación en que se encuentra una cosa, su comportamiento. Por ejemplo, que la cosa $a$ es $P$; que $a$ y $b$ están en relación en la relación $R$; que $a$ es un elemento del conjunto $A$; que $a$ es un todo del que $b$ es una parte; que $a$ existe. $O$ también que las clases $A$ y $B$ (así introducimos de repente otro elemento ontológico de orden superior muy especial, del que aún no habíamos hablado) están en la relación $R$; que todos los miembros de la clase $A$ poseen la propiedad $Q$; que la relación $R$ posee tales y tales propiedades; o que el predicado $P$ se determina ontológicamente en tal o tal forma.

He multiplicado los ejemplos para que salte a los ojos que una situación, aunque en principio implique a una cosa y una parte o un aspecto suyo que reconocemos como suyo, tiene una estructura del todo formal, o sea, trasladable desde el nivel ínfimo o cero, el de las cosas, a cualquier nivel superior (donde puede que se vuelve ambiguo no hablar más que de partes y aspectos de las unidades que allá nos encontramos).

Las"cosas" conocidas -regreso al lenguaje de la teoría básica del conocimiento, como en el § 1- son, pues, estructuralmente, situaciones, predicaciones. La noción de predicación es tan simple que sólo los ejemplos permiten captarla. En realidad, es indefinible. Ni aun con la fórmula célebre de Platón y Aristóteles: ti katà tinós; que no se podría quizá traducir sino, muy vagamente, como: 
algo-respecto-de-algo. Y sucede que cuando sabemos muchas predicaciones o situaciones en las que figura de un modo u otro cierto algo, decimos que conocemos este algo bien (o perfectamente, o aún imperfectamente).

Lo que ahora nos importa más es notar la obviedad de que la estructura predicativa es condición necesaria del conocimiento (en la expresión"conocer una verdad" y en la expresión "conocer algo porque se conocen muchas verdades sobre ello"), pero en absoluto condición suficiente. Está claro que las estructuras predicativas, además de conocidas, pueden ser ignoradas, sospechadas, puestas en duda, deseadas y temidas, odiadas y amadas. Una misma "cosa" y un mismo "objeto" son correlato de todas estas y aún de muchas más actitudes del sujeto. Una cosa no interpretada, un objeto sin sentido, ni siquiera son cosa ni objeto: no pueden ser vividos por nadie como tal cosa ni tal objeto. Pero habrá que diferenciar, al parecer, la interpretación básica, la mera posesión explícita de sentido, de todas las variadísimas actitudes que, sobre este fundamento, es todavía capaz de vivir el sujeto.

De este modo, parece que hemos de reconocer que la nuda interpretación es el comportamiento subjetivo elemental y fundador de todos los restantes. La aparición de sentido, con todo lo paradójica que sea por otra parte, es el comienzo mismo de la inteligencia y aun de la subjetividad propiamente dicha. Con ella queda establecido el objeto, que posee, justamente, estructura predicativa (y que, en la actitud inicial e ingenua, tendemos a identificar con la cosa trascendente misma).

Por este lado, se insinúa el pensamiento de que la unidad de la cosa quizá no sea, después de todo, la primordial y de orden cero sino, más bien, la de orden -1. Sin embargo, el recuerdo del caso que antes llamábamos 'autointerpretación' inmediata nos pone en guardia respecto de que no debemos abandonar la cautela.

En fin, lo que hemos avanzado significa que debemos atrevernos a diferenciar la "nuda interpretación" no sólo del amor, el odio, el deseo, el temor o la esperanza, sino también del dudar, el sospechar, el preguntar e incluso el conocer. Repitamos, por otra parte, que esta manifestación primordial de un sentido predicativo es una condición indispensable del conocimiento (de 
la situación designada por ese sentido), pero no es aún este conocimiento mismo. Lo un tanto paradójico, sin embargo, es que, al mismo tiempo, hemos de decir que esta manifestación primordial es, justamente y como tal, conocimiento de un sentido predicativo. Lo que sucede es que, como se trata en este caso de un sentido, su revelación, por perfecta y adecuada que sea (y tiene que serlo por principio, cuando lo que tenemos es una nuda interpretación o manifestación primordial), no es aún conocimiento de la cosa designada. Ésta es, como he dicho repetidamente, el auténtico polo que orienta el interés teórico.

Llamemos, como empezamos ya haciendo, intencionales a las actitudes del sujeto en cuanto se refieren, en ese modo indescriptible que es la relación vivida, consciente, subjetiva, a cualesquiera estructuras ontológicas: predicaciones, cosas, partes, aspectos, clases, relaciones. Así, la actitud intencional básica parece hasta aquí que sea la nuda interpretación: el dato inmediato de un sentido predicativo de máxima sencillez. El conocimiento, entonces, tanto en la acepción "enterarse de" como en la acepción "saber" (enterarse es un momento, saber es un hábito), desde luego es una entre las actitudes intencionales del sujeto. Mejor dicho, es, ya por el momento, al menos estas dos cosas diversas: por una parte, es la manifestación primordial de un sentido predicativo; por otra, es la posesión intelectual, exenta de error, de la situación a la que se refiere signitivamente ese sentido predicativo.

En efecto, aunque se emplea "verdad" y "verdadero" en otros muchos contextos más, es evidente que sólo se está propiamente en la verdad o en el error cuando se tienen (se viven momentánea o habitualmente) convicciones, creencias, opiniones; es decir, cuando se formulan explícitamente juicios o cuando se está en disposición de formularlos si la ocasión lo requiere (dado que ya se está viviendo de modo tácito la convicción correspondiente). En cambio, las actitudes intencionales que llamamos meras hipótesis, el pensar simplemente en tales o cuales cosas, no son ni sucesos ni procesos ni estados susceptibles de verdad. No lo son ni siquiera cuando, por ejemplo, la hipótesis plantea algo que, de ser creído, resultaría verdad. 
Al menos en un aspecto (el objeto intencional, o sea, el objeto como tal de la actitud intencional), hay extraordinaria semejanza, incluso igualdad, entre la mera hipótesis y el juicio; en otro aspecto, sin embargo, la diferencia es tan grande como para que la hipótesis no sea ni verdadera ni falsa y el juicio, en cambio, haya de serlo.

Quizá valga la pena acercarse a terminologías que ya se usaron otras veces cuando se miró a estos fenómenos. Digamos que la hipótesis y el juicio tienen, cuando poseen el mismo objeto intencional, la misma materia, aunque difieren formalmente. Si distinguimos así entre materia y forma de un juicio, nos vemos llevados a nuevas cuestiones acerca de qué sea lo verdadero por antonomasia. Y es que todo juicio será síntesis o reunión de estos dos aspectos (su materia y su forma), pero ocurre que la forma juicio será la misma en todos los juicios, ya sean verdaderos, ya sean falsos. Luego localizaremos en la diferencia material entre los juicios la base de la distinción entre juicio verdadero y falso, por más que entonces estaremos buscando el fundamento de la propiedad más admirable de los juicios en el aspecto que, lejos de serles propio, comparten con muchas otras actitudes intencionales que no son capaces de verdad ni falsedad. Lo que también es una paradoja.

Pero ¿hay tal identidad formal entre todos los juicios? También la pregunta suena a paradoja, puesto que está claro que, en general, todas las cosas de una misma clase comparten unívocamente la propiedad que las hace pertenecer precisamente a esa clase. Pero es que también es una trivialidad a la que nos induce el lenguaje el fenómeno de que es frecuente que algunos miembros de una determinada clase participen más que otros de la propiedad común a todos. Creemos, por ejemplo, en que existen intensidades diferentes de la misma cualidad y, en general, grados de perfección y de degradación.

En el lenguaje de todos los días está permitido preguntar, por ejemplo: ¿hasta qué punto estás seguro de eso que crees? Aquí, "eso que crees" designa la materia, que está siendo pensada y seguramente no creída por quien hace la pregunta, la cual toma a la forma del juicio por una magnitud que crece y mengua y que abarca desde la seguridad inquebrantable (la certeza) hasta la mera sombra de una sospecha a favor. 
Tanto si se piensa en la identidad de la forma de todos los juicios como si se piensa en que admite grados prácticamente infinitos, la mera hipótesis de una materia opinable aparece no como la síntesis de una forma peculiar y esa materia, sino como la pura ausencia de toda forma. A partir de esta ausencia o carencia, cualquier asomo de auténtica conjetura a favor del sí o el no propios del juicio, cualquier toma de postura que abandone la total abstención, sería ya un juicio, verdadero o falso.

A esta actitud tan particular que no es toma alguna de actitud, la llamaremos en general con el clásico término de representación, para oponerla al juicio. Pues bien, en cuanto atendemos al ámbito de las representaciones (que sería mejor llamar, menos clásicamente, presentaciones, como salta a la vista), comprobamos con sorpresa que entre ellas parece haber también multiplicidad de formas. Esta constatación nos da, sin duda, la oportunidad de estudiar más de cerca qué clase de diferencia es la que existe entre materias y formas de las actitudes intencionales.

\section{VI}

En efecto, cabe imaginar algo que quizá otro crea; pero cabe también que esa misma materia opinable dejemos de imaginarla y la volvamos correlato objetivo de una pregunta, de un examen o de una cavilación. Cabe, por otra parte, que nuestra imaginación de tal materia sea una ocurrencia fugaz o nos atormente como una idea fija; y cabe también que sea el fruto de nuestro ejercicio de tratar de introducirnos en la piel del interlocutor para entenderlo. Muy diferentes son las actitudes intencionales con identidad de materia y sin sombra de juicio, o sea, de forma judicativa. Y, por ello mismo, sin verdad ni falsedad. Aunque esta variedad no se puede remitir tampoco, como es evidente a la vista de los ejemplos, a la de las especies de un mismo género.

La teoría correcta acerca de estas innegables diferencias en la esfera de las presentaciones consiste en sostener que cada una de ellas va acompañada de un matiz emocional distinto. Éste es el verdadero responsable de una multiplicidad que al principio uno cree discernir en la naturaleza misma de las representaciones como tales. Por ejemplo, el interés por la respuesta y el 
deseo de que nos sea ofrecida acompañan en la pregunta a la mera presentación de la materia que ésta contiene. Otros intereses, otras valoraciones de la importancia positiva o negativa, en órdenes diversos de valores, son lo característico de cada uno de los tipos diferentes de representación que he enumerado. Todos coinciden en que todos son idénticamente presentación de una materia que podría ser la de un juicio; todos carecen por igual de una sombra siquiera de toma de postura judicativa. Pero, por decirlo de alguna manera, todos están trasfundidos por una determinada toma de postura emocional.

Se entiende que entre las tomas de postura que se llaman juicios y las tomas de postura que se llaman emociones hay una estricta diferencia genérica. Ninguna gradación nos traslada, pues, del ámbito del juicio al de la emoción ni del de las emociones al de los juicios. Si entendemos por actitudes intencionales tanto los actos que suceden en un instante como los hábitos (los estados propiamente dichos, que duran lapsos más o menos largos de tiempo y que se viven o con conciencia explícita o tácitamente: como disposiciones próximas o remotas de actos y actitudes explícitas en general), la primera clasificación omnicomprensiva de las actitudes o vivencias intencionales subjetivas que se nos ofrece es la que distingue las tomas de postura y las meras presentaciones; y luego pasamos a diferenciar estrictamente las tomas de postura teóricas y las tomas de postura emocionales o prácticas (breve y respectivamente: los juicios y las emociones).

A las presentaciones se las ha llamado representaciones y se las ha llamado también, con frecuencia y persistencia, ideas, desde los primeros estoicos. Su característica, repito, es la ausencia de forma, o para decirlo mejor, el hecho de que no se componen de otra cosa que de materia intencional en el sentido arriba definido; o sea, de aquello mismo que, alzado ante la existencia subjetiva por las meras ideas, puede ser, además de simple objeto de una representación, también objeto de una toma de postura, práctica o teórica.

Los juicios y las emociones no alzan nada nuevo ante la existencia subjetiva. Por el contrario, recogen -sin que esta palabra se refiera a procesos cronológicos, como dando a entender que antes ocurren las ideas que las emociones o los juicios- las objetividades que les suministran las ideas. Por encima de 
esta acción mínima y fundamental de la existencia que es la idea, juicios y emociones superponen una actividad propiamente dicha, diferenciada, en sentido estricto, en dos géneros.

Es evidente que estoy aquí llamando materia al objeto, a lo presentado; inevitablemente, llamo entonces forma al género de la actividad intencional de la existencia subjetiva que se superpone, cuando así ocurre, a la idea. Las formas son, simplemente, la emoción y el juicio. Muestran las formas un rasgo análogo, que estoy llamando toma de postura o actividad (frente a la relativa pasividad de la idea). Las tomas de postura son siempre o positivas o negativas: juicios afirmativos y negativos; emoción de atracción y emoción de repulsión.

¿Quién no ve la variedad enorme de las emociones? Entre el placer sensorial y la decisión heroica media una distancia ingente, toda ella formal o cualitativa: puramente hecho de actividad existencial en grados, matices e intensidades diversas. En los juicios, en cambio, no hay gradación ni pluralidad vastísima de especies. Sólo se excluyen de lo anterior dos especies, que inmediatamente ya son últimas, o sea, no susceptibles, a su vez, de más especificación: juicios afirmativos y juicios negativos. El resto de las diferencias entre juicios, o son materiales y no existenciales, o son distintas emociones concomitantes. Los aparentes grados de firmeza de la convicción no son verdaderamente tales, sino que consisten en cierta toma de posturas emocionales distintas, que deben explicarse como creencias, formalmente idénticas, en materias siempre diferentes. Por ejemplo, la certeza es la creencia, positiva o negativa, en tal o cual situación no modalizada; en cambio, la conjetura más o menos firme consiste en una pura y simple creencia, afirmativa o negativa, sólo que en una situación modalizada. Su materia, en vez de ser, por ejemplo, que Dios existe, es que es probable (en tal o cual grado) que Dios exista. Las probabilidades no son matices existenciales o formales, grados diversos en la intensidad de la creencia, sino modos que afectan al objeto del juicio. No son partes o aspectos de la existencia subjetiva sino, de alguna manera $-y$ dicho, lo reconozco, con cierto gusto por la paradoja-, partes o aspectos en el objeto. 
Con todo este bagaje a las espaldas, volvamos ahora al problema de cómo llevar a cabo una primera aproximación con buen éxito al concepto de la verdad.

\section{VII}

Progresar en esta cuestión pasa a través de determinar apropiadamente lo que diferencia y señala a los juicios frente a las emociones y las presentaciones. Se trata, para empezar, de una cierta valoración que no nos es posible extender sin más a ninguna otra de las dos grandes esferas de las actitudes intencionales. Y este valor es la corrección o la adecuación del juicio con las cosas, según vienen diciendo los filósofos desde los primeros tiempos en que esta disciplina se cultivó. Se trata de la concordancia auténtica entre el juicio, como actividad de una existencia subjetiva, y la realidad tanto extraexistencial como existencial. En un texto célebre del libro noveno de los Metafísicos, Aristóteles escribió que "está en la verdad el que cree que está separado lo que está separado y que está junto lo que está junto. Está en lo falso el que cree lo contrario de cómo son las cosas". Dejémonos guiar, por ahora, por las indicaciones que se contienen en estas palabras.

Hay en ellas, evidentemente, dos tesis de extraordinario alcance. La primera concierne a la naturaleza de la verdad; en la fórmula de Avicena, veritas est adeaquatio intellectus cum re. La segunda se refiere a la índole del juicio, y consiste en la exigencia de que todo juicio sea una síntesis, una conexión. Empecemos por ésta.

Ante todo, hay síntesis judicativas que merecen, sin duda, el nombre de juicios compuestos, porque poseen partes que a su vez son juicios (o de menor complejidad o ya simples). Los juicios compuestos se expresan en fragmentos lingüísticos que solemos llamar oraciones conjuntivas o copulativas, oraciones disyuntivas, oraciones condicionales, oraciones causales. En estos ejemplos, la síntesis está expresada, respectivamente, por las palabras: y (se entiende que uniendo formulaciones lingüísticas de juicios completos), $o$, si... entonces, si y sólo si, porque. 
En general, es evidente que la verdad de un juicio compuesto depende de la verdad de sus juicios componentes. En este sentido, los filósofos han solido hablar, como sinónimo de "juicios compuestos", de juicios hipotéticos, o sea, condicionados en su verdad por otros juicios que se encuentran formando parte de ellos.

Es muy interesante distinguir dos grandes casos en el carácter hipotético o dependiente de los juicios complejos. La lógica de los antiguos estoicos y la moderna lógica de las proposiciones elementales se han preocupado mucho por poner de relieve la diferencia que hay entre aquellos juicios compuestos cuyo valor de verdad (verdadero o falso) está unívocamente determinado por (o en función de) los valores de verdad de sus juicios componentes, y aquellos otros en los que, aún siendo conocidos los valores de verdad de las partes, queda alguna vez indeciso el valor veritativo que posee todo el juicio hipotético. Para el caso primero, la lógica contemporánea utiliza el término funciones de verdad, de origen puramente matemático. Naturalmente, cabe calcular estrictamente el valor de verdad de todas estas funciones, ya sea bajo el principio de bivalencia (que sólo es posible que un juicio sea determinadamente verdadero o falso) o, como ocurre en los cálculos no clásicos, bajo otros supuestos. En los casos en los que este cálculo no cabe, nos hallamos ante auténticos hechos, o sea, ante situaciones contingentes (como, por lo demás, sucede casi siempre a propósito de los juicios simples que entran en la complejidad de los juicios compuestos).

La unidad del juicio complejo es tan propiamente una unidad nueva respecto de las unidades que poseen de suyo sus juicios componentes, que cabe perfectamente el caso (recuérdese la llamada disyunción excluyente) de que siendo verdaderos todos los componentes sea cuando justamente es falso el juicio complejo. Y cabe también que la falsedad de los componentes redunde en la verdad del compuesto, como pasa en los llamados condicionales contrafácticos.

El problema arduo, si queremos comprobar la tesis de Aristóteles acerca del universal carácter sintético de todos los juicios, se nos presenta cuando descendemos a los juicios simples, o sea, aquellos que no pueden ser partidos en nuevos juicios de cuya verdad dependa de alguna manera la verdad del todo 
sintetizado. El término clásico para expresar la diferencia entre estos juicios simples y los complejos o hipotéticos es el de juicios categóricos. La cuestión, pues, es si son o no síntesis todos los juicios categóricos o predicativos.

Admitamos tentativamente que todos sean síntesis. ¿De qué podrían constar, a modo de materiales constructivos, tales síntesis? La respuesta sólo puede ser: de ideas o presentaciones, con completa indiferencia de si se viven o no trasfundidas de alguna emoción. Si ésta fuera la verdad, obtenemos que el juicio diferirá de la presentación en dos respectos y no sólo en el que antes puse de relieve. El juicio no sólo tiene forma de tal (tesis), mientras que la idea carece de ella; además, el juicio será siempre cierta síntesis de presentaciones, mientras que las presentaciones o ideas, aunque algunas veces pueden ser sintéticas también, no sería preciso que en todos los casos lo fueran.

Tendremos que subrayar que la forma sintética bajo la que se reúnen las presentaciones para formar la idea compleja que es la materia del juicio, aún no es la forma del juicio como tal. Aquella síntesis prepara el juicio pero aún no es este mismo; dispone toda la materia del juicio pero no supera el nivel del ámbito propio de la presentación.

Por cierto, no todas las síntesis de presentaciones prepararán inmediatamente el advenimiento de un juicio suministrándole toda su futura materia. De hecho, muchas síntesis de ideas no son, por ejemplo, más que conjuntos de ideas de cosas, o, quizá, la vinculación inmediata de una significación adjetiva o adverbial a otra sustantiva. La teoría que sostiene que todo juicio categórico es una toma de postura, afirmativa o negativa, sobre una síntesis de ideas, está pensando en una especie perfectamente determinada de tales síntesis como siendo la única que puede cumplir la función de dejar construida la materia del juicio categórico, análogamente a como sólo ciertas síntesis "materiales" de juicios disponen la materia compleja sobre la que puede advenir la forma del juicio hipotético.

Ya conocemos la expresión clásica para ese estilo único de síntesis capaz de suministrar su materia a los juicios simples: la predicación o categoría. Y la predicación se ha solido exponer como la vinculación a un sujeto de un predicado o categoría por medio de una cópula verbal. Se dice, por esto, que 
el significado de la cópula verbal es doble: consiste, por una parte, en la síntesis predicativa, que aún trascurre en el dominio de las ideas; pero cuando estamos expresando un juicio auténtico y no una mera hipótesis, la cópula también significa la tesis, o sea, la forma misma del juicio como tal.

La versión más completa de la teoría que defiende la naturaleza sintética de todos los juicios es, pues, aquella que sostiene que, sobre ciertos núcleos significativos carentes de toda forma, puramente materiales, se superponen, en primer término, ciertas formas sintácticas nucleares y elementales, materiales ellas también, que, por así decirlo, los preparan para que puedan desempeñar los papeles de sujeto y de predicado de un juicio categórico. Así, una idea o presentación estaría ya siempre integrada, incluso en el caso más simple, por un núcleo y una forma de núcleo, que no se expresa lingüísticamente casi nunca, como no sea por cierta posición en la frase o cierta entonación. $Y$ dejo a un lado adrede la diferencia entre la forma nuclear de sujeto y la forma de predicado, precisamente porque quizá todo predicado, como señala originariamente una parte, un aspecto o una relación de la cosa-todo-sujeto, no sea ya un núcleo (y su forma pura de predicado, por tanto, sólo sea una forma nuclear en sentido derivativo e impropio). Pero estas ideas nos vuelven a llevar demasiado lejos por el momento.

Continuemos con la versión más completa de tal teoría general sobre los juicios como síntesis. Más arriba del estrato de estas formas primeras o nucleares, la teoría habla de formas sintéticas o sintácticas, que cumplen el papel de enlazar presentaciones simples para construir con ellas presentaciones compuestas (por ejemplo: conjuntos, series ordenadas, sustantivo-adjetivo, sustantivo-adverbio, etc.). La más importante de estas formas de segundo nivel es la predicativa, porque es la única capaz de suministrar completa su materia a los juicios simples y, por ello, está íntimamente relacionada con toda posible teoría de la verdad.

Una vez que poseemos predicaciones, entendidas como estructuras sintácticas de ideas que, como vemos, contienen dos niveles al menos de formas sintácticas (las nucleares y la predicativa), ya es posible que sobre ellas se añadan las formas judicativas propiamente dichas, o sea, cualquiera de las dos especies de la tesis: la afirmación y la negación. 
En otra dirección, una vez que tenemos ya presentaciones completas, puede suceder que queden englobadas en alguna de las formas propias de la emoción que no suponen juicios, lo que nos obligaría a considerar si hay que conservar la noción de forma nuclear incluso en tales casos.

Es interesante observar que las predicaciones, sean o no de hecho materias de juicios categóricos, también preparan, aún en otra dirección, el advenimiento de un tercer nivel de formas de síntesis material (un segundo nivel, pues, de formas sintácticas). Me refiero, naturalmente, a las que construyen la materia compleja de los juicios hipotéticos. Por cierto que, en cambio, la forma propia de éstos sigue invariablemente siendo la tesis teórica (o afirmativa o negativa). Cuando pasamos del juicio categórico al hipotético, no aparecen formas nuevas del juicio. Las únicas diferencias son, de nuevo, diferencias materiales. Sólo sucede que, mientras en el juicio simple la cópula verbal expresa tanto la predicación como la tesis, en los juicios compuestos esta doble significación la soportan las palabras que expresan de suyo directamente la sintaxis de tercer orden (las que la gramática clásica llama conjunciones).

La diferencia de las palabras no debe ocultarnos el hecho de que la toma de postura, la tesis afirmativa o negativa, puede recaer exactamente igual sobre una predicación que sobre un sintagma de nivel superior, suprapredicativo. La dificultad no es mayor que la que ya se presenta en el juicio simple. En éste, en efecto, una síntesis de sujeto y predicado mediante la cópula sirve frecuentemente de base para la peculiar división en que consiste la tesis negativa. La misma soprendente contraposición (una síntesis material sobre la que se apoya una división formal) se observa en los juicios compuestos negativos. La negación de un condicional no es la destrucción del juicio condicional, sino una tesis referida a una materia que resulta ser un sintagma condicional. Afirmación y negación están coordinadas como especies de la tesis teórica o judicativa, y no se subordinan la una a la otra. La negación no supone previa afirmación ni la afirmación supone previa negación. Lo que manifiesta con mucha claridad que negar no es dividir, pace Aristóteles, puesto que dividir, que es una operación que transcurre sencillamente en el ámbito material o de las presentaciones, sólo es posible allí donde ha habido antes una composición. Luego no sólo negar no es dividir, sino que tampoco afirmar es componer, de nuevo pace Aristóteles. 


\section{VIII}

Pero la objeción más fuerte contra el derecho a tomar una teoría de este tipo como modelo general para la teoría de la verdad se sitúa en otro lugar muy diferente. $Y$ esta objeción nos hace comprender que existen, al menos y por lo pronto, dos tipos de la manifestación de la verdad bien separados, sólo para uno de los cuales es adecuada la ontología cuyas bases estamos poniendo. Me refiero a que ya sabemos que la manifestación de los objetos no es lo mismo que la manifestación de la manifestación de los objetos. Para la primera empleamos arriba el término interpretación, mientras que para la segunda no disponíamos sino de la palabra correspondiente: 'autointerpretación'. La interpretación es conocimiento de la cosa mediado por la presencia del objeto-signo; la 'autointerpretación' es conocimiento del conocimiento, sin mediación ninguna.

En este caso, el autoconocimiento es también una tesis, desde luego, sólo que no se funda en ninguna síntesis y, por lo mismo, desde el punto de vista material, tiene una estructura tan sumamente simple que es precategorial, presintáctica e incluso previa a la mínima complicación que es la presencia de núcleos y formas nucleares.

Si para el contacto con los núcleos objetivos hemos visto antes que debemos desmontar la predicación -nivel cero del análisis- y descender a un nivel -1 o abstractivo, pre-predicativo y pre-categórico, para el autoconocimiento el nivel inicial y único es prepredicativo y precategórico o precategorial en un sentido diferente, no abstractivo. En este segundo caso, no hay nada que desmontar mediante la operación reflexiva de la abstracción, que levanta la forma sintáctica y destapa, por así decirlo, las formas nucleares unidas a los núcleos materiales. Y es que en este caso del autoconocimiento no hay objeto y no hay distinción cosa-objeto-sujeto (distinción que sólo la interpretación, o sea, sólo la presentación, puede lograr y articular). A lo sumo, en el autoconocimiento la existencia subjetiva se capta a sí misma en su campo de presente, como nudo de presentaciones, juicios y emociones, notando de alguna manera que ella no está agotada en su autoconocerse. Es decir, queda todavía algo análogo a la diferencia entre objeto y cosa; pero sólo análogo. 
Únicamente cuando algunos principios de la agatología estén expuestos será posible volver sobre este lado primordial de la ontología (y de la teoría de la verdad). Ahora basta con la observación de que explorar el autoconocimiento inmediato quizá sea lo mismo, por lo menos parcialmente, que investigar no ya los entes extraexistenciales sino, de algún modo, su ser; investigación que, como se recordará, llamábamos ontología no general sino fundamental.

Para irla preparando, parece útil seguir dos direcciones en nuestro trabajo. Una continuará estudiando problemas puramente ontológicos que sólo indirectamente hemos afrontado hasta aquí; la otra deberá referirse ya a lo radical de la agatología.

\section{IX}

Hagamos un nuevo ensayo en los dominios de la ontología concediendo ahora que todo lo que existe propiamente sea particular, término que hemos evitado hasta este instante. Una palabra sinónima de particular es individual o individuo. Y concedamos, en segundo lugar, que todos los individuos pertenecen a una y sólo una de dos clases: las cosas y los objetos. Por cosas continuamos entendiendo las realidades primordialmente existentes: las que subsisten de suyo e independientemente; en una palabra clásica, el conjunto de la naturaleza. Los objetos son, en cambio, esencial y primariamente, signos naturales de las cosas aptos para darlas a conocer, que habrá que suponer (tercera concesión básica de esta teoría) que son suscitados por las cosas en ciertas otras cosas bastante especiales, llamadas sujetos. Los sujetos son, pues, las cosas capaces de representarse la naturaleza o, más exactamente, de sufrir o vivir la presentación de la naturaleza. El mundo real, pues, consiste, según este esquema tentativo, en un conjunto de cosas (aquíla palabra"conjunto" no significa que tengan las cosas del mundo mera relación arbitraria entre ellas), entre las que unas son sujetos y las otras, incapaces de actitudes intencionales, podrán denominarse, como en la tradición, cuerpos.

Como la realidad del conocimiento es insoslayable en cualquier ontología que se comprenda a sí misma, subrayo que esta ontología que ensayo en una nueva dirección pretende, al hablar de objetos como lo hace, sencilla- 
mente respetar la noción intuitiva de que una cosa no puede conocer otra cosa más que si la cosa conocida influye en la conocedora trasladándole un signo de ella misma, y precisamente un signo que, como mínimo, se parezca fielmente al origen del que procede.

Así pues, los sujetos son, en principio, susceptibles de poseer dos series muy distintas de partes y de aspectos. Una serie será la de sus partes naturales como pedazos o componentes que ellos son del mundo; esta serie se asemeja a la única que pertenece a los cuerpos. La otra serie de las partes y los aspectos de un sujeto serán, justamente, sus objetos. Por el momento, no entro a dilucidar qué clase de parte o aspecto es aquello gracias a lo cual un sujeto se conoce a sí mismo; o sea, dejo por ahora a un lado la cuestión del autoconocimiento o 'autointerpretación'.

También puedo decir que los particulares reales son o bien arquetipos, modelos originales (cosas: cuerpos y sujetos), o bien traslados subjetivos (objetos). Recordemos el dato de partida esencial: que carece de sentido decir que el conocimiento es el simple suceso de que una cosa o una parte de una cosa pasa a ser parte de otra cosa. La mera inclusión de algo real en algo real mayor no describe ni explica de ninguna manera este suceso que es la presentación de una cosa en otra (o el juicio verdadero que una cosa realiza sobre otra o sobre sí misma). Por muy ingenua que se proponga ser la clasificación de cuanto hay, no conseguirá evitar el desdoblamiento del significado de todos los términos ontológicos: primitivamente, designan estos términos la realidad arquetípica y simplemente tal; pero además significan luego la realidad-objeto. Cabe llegar a decir que no sólo "realidad", sino también "mundo", "naturaleza", "todo", "parte", "inclusión", "aspecto", son palabras con doble sentido, pero no equívocas. El sentido originario, repito, es el que alude a la realidad arquetípica de las meras cosas naturales; el sentido derivado y analógico es aquel en que lo mencionado es, digámoslo con expresión clásica y ya conocida, no el mundo sino la representación o idea del mundo.

Anotemos esto bien: una presentación (o idea, o representación) se puede tomar en dos perspectivas muy diferentes. La primera no ve en ella lo que tiene justamente de idea, de objeto, sino sólo lo que tiene de parte real de 
una cosa del mundo (de un sujeto). En este sentido, las ideas no se distinguen del resto de las partes del mundo más que por el hecho de ser partes reales tan sólo de sujetos y no exactamente de cuerpos (aunque sobre este problema habrá mucho más que decir). Un sujeto se distingue de un cuerpo básicamente porque sólo en los sujetos se pueden hallar, entre las partes que contienen, ideas u objetos.

Por supuesto, cabe una segunda mirada sobre las ideas que desatiende lo que tienen en común con el resto de las cosas naturales y trata de captar su extraordinaria originalidad, la cual estriba en que una parte de una cosa pueda ser, de suyo, el signo de una cosa distinta. Y como este signo tiene, al menos a veces, si es que conocemos con verdad alguna cosa ajena a nosotros mismos, que asemejarse mucho y muy perfectamente a la cosa designada por él, lo llamaremos tentativamente imagen o icono de su original. En definitiva, una idea, además de parte real de un sujeto, es la realidad-imagen de una cosa diferente del sujeto y diferente, como arquetipo suyo, de la idea misma.

Me valdré en las páginas siguientes de dos expresiones medievales que usó Descartes en el texto capital de la modernidad que son sus Meditaciones metafísicas. Espero que alivien un poco la dificultad lingüística que hay a la hora de reflejar las dos significaciones análogas de todos los términos ontológicos. La realidad simplemente tal o arquetípica, la de los cuerpos y los sujetos, la llamaré realidad formal (ya que este adjetivo significaba originalmente "propiamente dicha", "en acto"); a la realidad-imagen, derivativa y analógica, la llamaré realidad objetiva (de hecho, desde el principio venimos hablando de "objetos").

Y como he empezado a emplear términos de prosapia histórica para esta zona de la ontología, continuaré así. Este marco tentativo que estoy ahora explorando sostiene el monismo del ser particular. La noción de idea u objeto que he definido está en el fundamento de la teoría sobre el conocimiento que se denomina representacionismo. Hay muchas clases posibles de representacionismo. Por el momento estamos hablando de representacionismo icónico y causal (o sea, de que el objeto es una imagen de la cosa en el sujeto causada por la acción real de la cosa sobre el sujeto, y suficientemente semejante a la cosa-causa como para darla bien a conocer, al menos en ciertos casos). 


\section{$\mathbf{X}$}

Tomando en cuenta el gran número de los pensadores que la han sostenido, una tesis plausible es la que afirma que lo que existe, puesto que todo es de índole particular, es una multitud incontable, un conjunto ilimitadamente numeroso de individuos. Y ahora se trata de ahondar un poco en los significados de "particular" y de "individuo", sin seguir dándolos por puramente sinónimos e indefinidos.

Para lo que acabo de decir, es indiferente que hablemos de seres formales o de seres objetivos: la condición de particular, que se extiende por encima de la diferencia entre realidad formal y realidad objetiva, es la que trae consigo la multiplicidad sin límite. Por ello, a las innumerables realidades formales o actuales les corresponden en principio innumerables iconos suyos naturales, cada uno de los cuales, por cierto, seguramente será reflejado en un nuevo icono u objeto (¿por qué un objeto no va a tener iconos suyos también, cuando a veces lo que conocemos es, evidentemente, la imagen de una imagen de una imagen?). Más sencillo sería pensar que las cosas y las ideas constituyen dos conjuntos infinitos de la misma cardinalidad que el conjunto de los números naturales, y que hay entre ellos exacta correspondencia uno a uno de todos sus elementos; pero es poco probable que sea así.

La definición clásica de individuo consiste en que este ser es idéntico sólo a sí mismo, pero diferente de todo lo otro que él: unidad cerrada, en este sentido, sobre sí misma. Pero valiéndonos sólo de este concepto no encontramos el fundamento de que deba haber una cantidad infinita de individuos. Tampoco lo encontramos analizando la noción clásica y lógica del particular: un particular es una unidad óntica que no admite ser predicada o dicha más que de sí misma. Los particulares son, pues, singulares, o sea, seres que se toman de uno en uno: seres que no están en muchos. Hay, entonces, al menos un aspecto común a las nociones de individuo y de particular o singular: la irrepetibilidad. El individuo no es común más que a sí mismo; o sea, no es común en absoluto. Y lo mismo le sucede al particular o singular.

Supongamos una unidad óntica, un ser, que en su noción misma se oponga contradictoriamente al individuo y al particular como seres irrepetibles. Será 
aquella que precisamente sea común a varios, repetible en varios y, por ello mismo, susceptible de ser dicha con verdad a propósito de varios entes. En definitiva, las nociones contradictorias de lo repetible y lo irrepetible son las nociones de lo común y lo singular, lo universal y lo individual, lo genérico o específico y lo particular.

La tesis del monismo del ser particular consiste, negativamente, en afirmar que no hay ni cosas ni ideas universales: que no existe nada universal, ni formal ni objetivamente. Pero volvamos al problema de la relación que pueda haber entre la irrepetibilidad del individuo y el número sin cuenta de los individuos. Y lo único que se ve es que una unidad irrepetible no exige existir al lado de otras tan individuales como ella. En caso de que haya más seres, sólo sabemos de antemano que, conforme a esta tentativa ontológica, ninguno será idéntico más que a sí mismo. $O$ más bien: asimismo sabemos que ningún ser, si hay más de uno, compartirá con ningún otro ninguna parte suya, ningún aspecto suyo; porque, de lo contrario, esa parte o aspecto sería un ser repetible, común y universal.

En otras palabras: todo, si es que existe alguna pluralidad, será siempre nuevo respecto de cuanto ya haya existido; de hecho, radicalmente nuevo. A lo sumo, quizá le esté permitido guardar algún parecido con algún otro ser; pero este mismo parecido será un caso único e irrepetible. Naturalmente, el recuerdo de los iconos-objetos empieza inmediatamente a inquietar a quien va elaborando este monismo; pero, como de costumbre, prefiero esperar a otras inquietudes aún más graves, duras y decisivas.

Si admito, pues, que el individuo lleva en sí mismo el principio de su unidad y de su unicidad irrepetible, no por ello me veo llevado al pensamiento de los infinitos individuos reales, que es también una parte del monismo usual de lo individual. Tengo aún que introducir alguna noción más. Me sigue faltando completamente la raíz de la multiplicidad.

Para hallarla, tendré ante todo, según me parece evidente, que concebir un medio uniforme que me sirva de receptáculo de la muchedumbre de los particulares: algo así como un lugar con muchos lugares. Sobre el fondo de este nuevo pensamiento, la irrepetibilidad del individuo viene ahora a ser 
la prohibición de que se lo identifique en ningún aspecto o parte, y menos todavía en todo, con otro individuo cualquiera, bajo el supuesto de que pueda existir otro individuo cualquiera en algún otro lugar de este medio uniforme. Sigue, pues, como es evidente, faltando el principio que haga positivamente inteligible y efectivamente real la multiplicación de existentes singulares.

Pero, de entrada, habrá que profundizar en la determinación de este medio uniforme, primera condición necesaria de la multiplicidad, en el que, como en un lecho, se extiende la realidad del mundo. La primera sugerencia viene de la noción misma de que es irrepetible lo que no se encontrará una segunda vez. Pero no hay que confundir el carácter temporal que tiene toda búsqueda (aquí, la de una repetición) con la existencia independiente de los individuos irrepetibles. Por el contrario, parece más natural empezar concibiendo el lugar de lugares en que se hace real el mundo como extensión pura, perfectamente inmóvil y perfectamente unitaria (o sea, no troceable, sin partes en el sentido fuerte de esta expresión, como lo definimos antes).

Así, la condición radical para la multiplicidad ilimitada de las cosas particulares que componen el mundo parece que ha de ser el espacio ilimitadamente extenso, el cual tiene que ser concebido como una no-cosa e incluso como una no-relación, ya que cosas y relaciones son posibles sólo sobre el fundamento del espacio (imaginemos a qué relaciones me refiero ante todo: innumerables "junto a" individuales, que forman un conjunto que necesariamente posee mayor cardinalidad que el conjunto de las cosas).

Pero aquí sí que hay ya que reconocer la insuficiencia capital de los pensamientos que voy desarrollando, y que no es otra que toda esta descripción ontológica, como toda otra, claro está que transcurre en el ámbito de la representación, antes que en el ámbito del mundo mismo. Si es verdad de alguna manera la tesis representacionista, entonces por fuerza es verdad que lo que inmediatamente hay, en tanto que conocido, no es el mundo actual y formal mismo, sino más bien la idea del mundo, el espectáculo del mundo, el signo o icono del mundo: el mundo mismo como realidad objetiva, como representación. 
Ahora bien, sucede -de aquí la importancia de tomar ya en cuenta esta insuficiencia- que, en cuanto uno intenta tomar seriamente en consideración las consecuencias de que el ser inmediato sea el ser objetivo y no el ser formal, inevitablemente repara en el hecho de que el espectáculo del mundo es sucesivo e incluso histórico, como ya dijimos, y no simultáneo. En otras palabras, la novedad inagotable de que hemos hablado es la novedad de cada ahora, o sea, de cada nuevo objeto llenando parcialmente este sujeto que soy yo. La experiencia en la que de verdad tiene su origen la tesis de la variedad sin límites del mundo es la experiencia de que cada ahora, cada idea-ahora, cada objeto-ahora, es irrepetible.

Ni que decir tiene que la unidad íntima entre un ahora y un objeto es otra consecuencia necesaria de la ontología tentativa que estoy desarrollando. Es lo mismo hablar de la individualidad e irrepetibilidad de las ideas que decir que ningún ahora vuelve a ser ahora. A esta nueva luz, el medio uniforme original en el que ha surgido el pensamiento del mundo y su variedad formidable e incontrolable no es ya el espacio sino el tiempo. Y no el tiempo como una cosa o una relación, sino el tiempo a título de condición de la existencia individual de cada cosa y condición del "junto a" de la multiplicidad de las cosas.

En la nueva perspectiva, el espacio se muestra como introducido en cada ahora en la medida en que un objeto-ahora es una cosa o un conjunto de cosas objetivas en el espacio objetivo (y no en el espacio formalmente existente). Podría ser útil que nos atrevamos a emplear una expresión del estilo de que el ser inmediato (o inmanente) suele consistir en muchos lugares objetivos llenos (no meros lugares vacíos), que vienen a parecerse a cuentas en el rosario de los objetos-ahoras, engranados en el hilo uniforme de la nocosa y no-relación que llamamos el tiempo.

\section{$\mathbf{X I}$}

Hagamos pertenecer a nuestro ensayo ontológico otras dos afirmaciones muy plausibles: que existen muchos sujetos y que se da la comunicación intersubjetiva. A fin de cuentas, aquellas proposiciones que están implicadas en el hecho mismo de escribir una ontología no pueden pasarle a ésta inadvertidas. 
Ahora bien, el material fundamental de la comunicación intersubjetiva sólo puede estar constituido por los objetos particulares que vive cada sujeto; $y$ es evidente que la particularidad o irrepetibilidad absoluta de los objetos opone un obstáculo gravísimo a la posibilidad de la comunicación.

Un modo sencillo de entender ésta parece que lo ofrece el pensamiento de que en ella se trata de trasladar un objeto de un sujeto a otro, valiéndose de palabras o gestos del cuerpo. Pero está claro que el envío de un objeto a otro sujeto sólo tendría éxito cuando el receptor repitiera el mismo objeto que primero sólo se hallaba en el sujeto emisor. Y nuestro monismo nos ha prohibido la repetición, entendida en el sentido estricto como identidad de dos particulares.

Tendremos, pues, que recurrir a una teoría de la comunicación que intente operar tan sólo con objetos parecidos; por ejemplo, podemos pensar en que se asocie en un sujeto cierto nombre con cierto objeto, y en que la exteriorización de ese nombre ante otro sujeto evoque en él otro objeto particular, asociado con otro caso anterior muy similar (del "mismo nombre"). Si los objetos afines se parecen lo suficiente, la comunicación será posible, aunque esté siempre enturbiada por la imposibilidad de compartir plenamente con nadie los objetos propios. Examinemos la consistencia de una teoría como ésta.

Como prueban la variedad enorme de las lenguas y mi propia capacidad para inventar nuevos sistemas lingüísticos, no hay duda de que las palabras no son signos naturales de los objetos; y tampoco hay duda de que no pretenden, salvo de modo excepcional, representar icónicamente el objeto que significan. Pero es que, además y sobre todo, aun dejando a un lado la artificialidad arbitraria de los signos lingüísticos, es evidente que no cabe postular que se logre lenguaje alguno dotado con un conjunto infinito de nombres particulares, o sea, con un conjunto de ellos que tenga la misma cardinalidad que el conjunto de los objetos particulares. Lo anterior se entiende si queremos garantizar que el lenguaje, en uno de sus usos básicos, vehicule la comunicación intersubjetiva.

Pensemos, en otra dirección, este conjunto infinito de nombres propios, es decir, de nombres que sólo significan un objeto particular, al que han sido asociados 
arbitrariamente por un sujeto que ha vivido alguna vez ese objeto. De repente comprendemos que nuestra teoría también nos impide explicar el origen del lenguaje en general, porque el sujeto que vive sus objetos no tiene la menor necesidad de fijarlos lingüísticamente, ya que todos se le ofrecen directa, inmediata e irrepetiblemente. No precisa de signo alguno de ellos. Pero es que, además, dada la irrepetibilidad de los objetos, está del todo clausurado en su ámbito y no es capaz, ni aunque conciba la loca idea de una posible comunicación, de dedicarse a repetir de algún modo objetos dentro de su conocimiento para irles ligando a los semejantes un nombre uniformemente semejante. Con un lenguaje puramente privado de cada sujeto no se puede pensar la comunicación; pero es que el monismo del ser particular lleva incluso a la consecuencia del establecimiento de ningún lenguaje privado.

Finalmente, para llevar al extremo la bancarrota lógica de la concepción del lenguaje como un conjunto infinito de nombres propios en exacta correspondencia biunívoca con el conjunto de los objetos particulares, consideremos que ningún sujeto que esté encarcelado en algún sector de estos dos conjuntos infinitos se entenderá a sí mismo ni entenderá en ninguna medida su mundo propio. Si no cabe significar con un solo nombre repetible muchas ideas, el aprendizaje, el progreso en el conocimiento, desaparecen, igual que la comunicación.

Entonces, sólo es saber que dé lugar a más saber (saber propiamente dicho) el que extrae del caso particular alguna información aplicable a otros casos; lo que sucederá tanto mejor si la información es fijada en términos lingüísticos intersubjetivos. No puede decirse que sea saber la actitud intencional que se limita estrictísimamente a la captación directa de un objeto particular.

Pero en vez de perseguir directamente la importantísima tesis que de aquí se sigue respecto de la naturaleza de los objetos, nos conformaremos de momento con considerar mejor el hecho, que acabamos de comprobar, es decir, que aunque no quepa poner puertas al campo de la variedad abigarrada de los objetos, es absolutamente imprescindible ponérselas al también abigarrado dominio de los nombres propios, si queremos que éstos nos sirvan para algo, o sea, que contribuyan a nuestro progreso tanto cognoscitivo como comunicativo. 
Mejor dicho: en realidad, no tenemos que limitar lo ilimitable de los nombres propios, sino que más bien debemos ampliar el terreno de las expresiones lingüísticas dando en él cabida a un conjunto nuevo, a una nueva categoría de tales expresiones, una de cuyas funciones será la de hacer posible la existencia misma de los nombres propios útiles. Esta categoría esencial para que haya lenguaje, para que haya autocomprensión, para que haya ciencia, aprendizaje y comunicación intersubjetiva, es la de los nombres comunes, generales o universales, ya que cada expresión de esta clase significa muchos objetos.

El nombre universal lo es porque nombra de algún modo toda una multiplicidad de objetos; pero también vemos que es absurdo pensar que esta multiplicidad de objetos es, toda entera, la que se le asocia en cada caso en que comprendemos el nombre en cuestión. Y como tampoco puede pensarse que lo asociado sea una porción de la multiplicidad de objetos correspondiente, porque entonces el nombre sólo nombraría ese sector de objetos, no cabe sino admitir que al comprender el nombre universal es que se le asocia un objeto singular, signo de los múltiples objetos particulares que son los significados o nombrados por el nombre. Si pensamos en todos los hombres o en todos los números naturales, o simplemente en todos los objetos familiares de nuestra propia casa, es evidente que no se nos presenta auténticamente cada uno de los miembros de esos conjuntos en el instante en que, sin embargo, la comprensión de su nombre universal nos hace, efectivamente, pensar en la totalidad de ellos. Pero es que incluso en los casos en que la cantidad de los elementos del conjunto en que pienso al nombrarlo con su nombre común es suficientemente pequeña como para permitir representación auténtica de cada uno, vemos que sólo cabe pensar en la multiplicidad en tanto que unida: sólo es posible representarla en la medida en que tal representación es unitaria y no tan varia como los objetos realmente abarcados por ella.

Ahora bien, si cuando entiendo un nombre universal capto un solo objeto pero nombro todo un conjunto de objetos, ese objeto único que hace posible la relación de nominación no podrá ser nunca nombrado por un nombre propio. En la teoría semántica, llamamos habitualmente significado al objeto que se entiende al comprender un nombre. En el caso de los nombres 
propios, el significado y lo nombrado (lo significado) coinciden; en el caso de los nombres universales, divergen.

Siendo así, el problema de la nominación universal es esencialmente el de la relación intrínseca que exista entre el objeto unitario que es el significado del nombre y los múltiples objetos particulares que integran el conjunto de lo nombrado. Como de costumbre, ensayamos primero la solución más fácil posible, que aquí es postular que el significado sea de naturaleza universal, en el sentido de que el objeto que él es se encuentre repetido idénticamente en cada uno de los objetos particulares nombrados. La mera presencia de esta parte idéntica en todos ellos explicaría sin necesidad de más recursos la relación de nominación, sólo que habrá que distinguir a propósito de ella lo directamente nombrado, que será el significado universal, de lo indirectamente nombrado, que es cada uno de los objetos particulares que contienen como parte idéntica en todos al objeto-significado.

Sólo nombro entonces a los particulares a través de la mención explícita de su pertenencia al mismo conjunto, la cual, a su vez, queda explicada por la presencia en todos de cierta parte idéntica, que es la que define el ámbito posible o "extensión" del conjunto. Aunque al significado podamos decir, como acabamos de hacer, que lo nombramos directamente, la verdad es que lo nombramos sólo en la medida en que estamos pensando explícitamente en que tiene un ámbito de particulares. No lo nombramos pensando en él desligado de su relación intrínseca con esos particulares posibles. Lo que quiere decir que incluso en esta perspectiva el significado sigue ejerciendo, fundamentalmente, un papel mediador en la nominación.

Para el monismo del ser particular, admitir que en la nominación haya un significado de esta naturaleza es, desde luego, imposible, a no ser que lo tratemos como un mero "ente de razón", o sea, una ficción del entendimiento. $Y$ una relación cognoscitiva que usa semejante mediador va ya lastrada desde su inicio.

Pero ¿qué sucede si mantenemos el objeto-significado declarándolo un particular? El nombre universal ejercería entonces su función significativa por haber sido asociado con un objeto particular extraído del conjunto de 
los objetos nombrados. Ahora el significado se incluye, pues, entre lo nombrado, por más que esto sea múltiple y aquello, uno y único. Un particular que capto me hace referirme a todos los demás particulares de su mismo conjunto. ¿Cómo es posible? Será porque él hace las veces de todos los demás, es un representante suyo. No que lo sea por sí mismo: esta relación representativa se la ha añadido mi entendimiento al seleccionarlo de entre todos sus congéneres (me da igual por qué razón). La relación misma es un "ente de razón", un invento mío utilísimo; pero con algún potente fundamento en las cosas mismas, que tengo que observar más de cerca.

En primer lugar, con independencia del sujeto y su capacidad inventiva, tiene que haber alguna relación natural entre los múltiples particulares, tal que uno cualquiera pueda hacer de signo de los demás si alguien lo selecciona para esta función (y le añade a la dicha relación natural otra "de razón" meramente). Como se trata de particulares, se excluye que la relación natural en cuestión sea ahora otra vez la de estar presente uno en todos.

En efecto, si cierto número de particulares está reunido en una clase o es, en general, reunible en alguna clase, ya que por los principios del monismo de lo individual no pueden tener nada verdaderamente en común, deben, al menos, mantener ciertas relaciones, que seguramente quedan descritas de modo suficientemente plástico con decir que tienen que consistir en algo así como un parecido general, un aire de familia. Un grupo de cualesquiera elementos se dará un aire de familia propio sólo de ese grupo, que podrá ser compartido abiertamente por más particulares más adelante, como de hecho sucede con los parecidos familiares. Y así la relación que mantienen o que fundan todos los particulares posibles de una clase es tan particular como la que mantienen entre ellos los elementos de cualquiera de sus subconjuntos.

La nominación universal se constituye luego sobre una ficción que, en el mejor de los casos, va montada como una superestructura que cubre adecuadamente todo el ámbito del natural aire de familia. Y es que al usar el nombre como universal no empleo un particular a modo de vaga imagen de ciertos otros particulares, sino que asumo la ficción, de acuerdo con esta teoría, de que las diferencias de todos los objetos nombrados se anulan en la unidad del único que está realmente captado como significado. No es posible la nominación 
universal, cuando la intento explicar en estos términos compatibles con el monismo del ser particular, más que si, en el desempeño de su función de representante, el objeto particular que es el significado oculta, por así decir, cuanto lo diferencia. Aunque la verdad es que él se diferencia de manera particular, o sea, distinta, de todos los objetos a los que está representando. Lo capto como absolutamente uno cualquiera entre todos los particulares de su clase, y sólo en virtud de esta ocultación remite enteramente por igual a todos.

Si analizamos el asunto con alguna finura, vemos que la ficción no está propiamente sólo en ese ocultamiento, el cual, en realidad, es desatención que sabe ejercer con pericia un entendimiento maduro. En lo que realmente consiste es en que el entendimiento procura obnubilarse respecto de la infinita variedad de lo real y piensa en este particular, al que la atenta desatención selectiva ha vuelto en algo así como una sombra de sí mismo, como si de verdad coincidiera con el resto de espectros de particulares que podríamos conseguir sobre la base de otros casos concretos. Este como si es el responsable de que la nominación universal no se tornasole en una absoluta equivocidad, la cual, justamente, ya no sería nominación universal sino nominación propia que usaría siempre, estúpida y caóticamente, el mismo signo. Es como si el representante universal, gracias a esta depuración que lo vuelve espectral, se hubiera convertido en universal de suyo y no meramente por la virtud de una sobreañadida "relación de razón".

\section{XII}

Si revisamos las dos concepciones alternativas que acabo de exponer acerca de la naturaleza del objeto-significado que es el medio para la nominación universal, destaca en seguida que les es común a ambas una característica interesantísima. El objeto universal compartido por los particulares posee menos contenido que cualquiera de éstos, ya que el contenido del universal es parte idéntica dentro de sus particulares. Por su parte, el objeto particular representante de todos los de su círculo de semejanza no posee de suyo un contenido menos variado y múltiple que cualquiera de sus congéneres, pero se ve reducido a espectro de sí mismo por la obra de la razón dispuesta a usarlo como instrumento comunicativo básico. Es, pues, común al significado- 
representante y al significado universal el hecho de que, tomados exactamente como funcionan al mediar la nominación universal, ambos son entidades más sencillas que sus particulares o sus representados. Y además, este tipo de mayor sencillez se puede entender perfectamente como el producto, en los dos casos, del trabajo del entendimiento depurando el contenido de alguno o muchos o todos los particulares de una clase.

La acción de prescindir de cierta ganga está, pues, en los dos procesos. A este primordial reducir, prescindir o cortar (praecisio, abstractio) lo completa en seguida, como el movimiento sintético que sigue de cerca al movimiento analítico, la visión de todos los particulares bien desde el representante, bien desde el objeto universal. Primero se asciende de lo particular a lo general (a lo que es de suyo general o, respectivamente, a lo que sólo funciona como si lo fuera); después se desciende desde lo general a lo particular. En este descenso, en esta síntesis en el segundo momento, es donde propiamente luce la relación entre lo uno y lo múltiple que es constitutiva del fenómeno básico de que haya de alguna manera clases de cosas. Como los dos momentos son solidarios, su reunión merece un nombre adecuado, y la tradición nos ofrece el término abstracción. Podemos llamar abstracto al objeto que resulta de la primera fase de esta doble operación y, en cambio, concreto, a uno cualquiera de los objetos particulares tomado o como punto de partida o como punto de regreso de la abstracción.

En el momento analítico, hay que prescindir de lo diferencial de los concretos sobre los que se opera la abstracción: hay que dejar a un lado las diferencias individuales. Si se reconoce que el significado es un objeto universal, entonces es que realmente el entendimiento habrá prescindido de todas las diferencias individuales de los concretos, porque le era posible por principio hacerlo (ya que el monismo del ser particular se desecha como teoría imposible). Si se piensa, en cambio, la abstracción todavía dentro de este monismo, la operación del entendimiento no puede ser la de eliminar de verdad las diferencias individuales. Sencillamente, esto es un imposible. Consistirá en el duro esfuerzo de no tenerlas en cuenta, de hacer como si no existieran. Ellas existen, pero yo no las miro, y así utilizo el producto de la abstracción a sabiendas de lo convencional de mi manera de obrar. Aquí, la relación del 
abstracto con sus concretos es tal que, en todo concreto, si hubiera procedido a desatender lo diferencial, mejor dicho, lo más diferencial, lo que no tiene que ver con el aire de familia compartido, habría encontrado al final un producto que me serviría para lo mismo que este que ahora realmente tengo: como si ambos fueran perfectamente intercambiables. Todos los concretos, los posibles productos de esta atención desatendedora, vienen a ser lo mismo, si tiene uno la paciencia de concentrarse en lo más parecido hasta hacer que todo lo demás escape de nuestro actual objeto.

La disyuntiva es, pues, hasta aquí, la que hay entre una teoría de la abstracción basada en la eliminación de las diferencias individuales y otra teoría que sólo admite la expulsión hasta los márgenes exteriores del objeto de lo que hay de menos parecido en un concreto que está en un determinado círculo de semejanzas. Cuando digo "menos parecido" en realidad quiero decir: aquello que no me atrevo a asumir que haya de darse, más o menos, en todos los miembros de la clase.

Antes de decidir por alguna de las ramas de esta alternativa que no parece ofrecer otras salidas, y sin limitarme a recordar que encontramos inconsistencias graves en la teoría del significado universal, conviene que examinemos con cuidado la naturaleza de los concretos, a fin de descubrir -de revisar, más bien-qué son en realidad las diferencias individuales. Una vez que se entienda bien en qué consisten éstas y cómo se hallan presentes en los concretos, se sabrá qué es lo que podría quedar si me deshago de ellas.

Para empezar, supongamos por un espacio de tiempo, olvidando algunos aspectos de pasados análisis, que compartimos con la mayoría de la gente y quizá con el dudoso sentido común que lo complejo se origina de lo simple, y no lo simple de lo complejo. Y para evitar aún mejor dudas inmediatas sobre semejante postulado, concedamos que, más que en el ámbito de las cosas, su terreno de aplicación es el del conocimiento. Si en las cosas no estamos nada ciertos, en el conocimiento, o sea, en la esfera realmente inmediata (la de la "realidad objetiva") sí parece, en cambio, muy plausible que la simplicidad sea el origen de la complejidad, tanto en orden lógico como quizá, incluso, en el cronológico. 